\title{
LORQUEANDO: A LITERATURA COMO VIVÊNCIA ESTÉTICA DE SI E DO OUTRO NA EDUCAÇÃO A DISTÂNCIA
}

\author{
VIDEO POEMS OF GARCIA LORCA: LITERATURE AS AESTHETIC EXPERIENCE OF SELF AND THE \\ OTHER IN DISTANCE EDUCATION
}

Fabricia Teixeira Borges

Doutora em Psicologia pela UNB. Docente do Programa de Pós-Graduação em Educação da UNIT.

Andrea Cristina Versuti

Doutora em Educação pela UNICAMP. Docente do Programa de Pós-Graduação em Educação da UNIT.

Angélica de Fátima Piovesan

Mestranda em Educação pela UNIT.

Programa de Pós-Graduação em Educação Universidade Tiradentes (UNIT)

Aracaju - SE - Brasil

Endereço:

Av. Murilo Dantas, 300

Aracaju - SE

CEP: $49032-490$

E-mails:

fabricia.borges@gmail.com

andrea.versuti@gmail.com angelicapiovesan@hotmail.com

RESUMO

Este artigo apresenta um estudo sobre a construção identitária docente a partir da educação estética da literatura na Educação a Distância. Para tanto, analisamos o processo dialógico e estético de criação de um conjunto de videopoemas de Garcia Lorca por um professor (Dom). Neste processo, atentamos para as especificidades da cibercultura e da linguagem audiovisual e hipertextual consideradas pelo professor na construção estética de si e de que forma isto impacta tanto o aluno quanto o professor, favorecendo o encontro de ambos. No videopoema, o professor apresenta arte e também vira arte. Concluímos neste estudo que sua construção estética de si ocorre de forma sistematicamente organizada pelo contexto e pelas interações do ambiente virtual de aprendizagem - AVA - no qual está inserida. Compreendemos a identidade como um conjunto de posicionamentos organizados semioticamente como uma estética de si que se configura pela interação com o outro.

PALAVRAS-ChAVe: Arte. Estética. Identidade. Docência. EaD.

ABSTRACT

This article presents a study on the construction of teachers' identity based on the aesthetic experience of literature in distance education. For this purpose, we analyze the self-dialogic and aesthetic process of creating a set of Garcia Lorca's video poems, by a teacher (DOM). In this process, we look at the specifics of cyberculture and the audiovisual language and hypertext considered by the teacher in the aesthetic construction of self, and how this impacts both the student and the teacher, promoting the meeting of the 
two. In the video poem, the teacher presents art and also becomes an art representation. We conclude, in this study that the aesthetic construction of self occurs systematically, organized by the context and interactions of the virtual learning environment (VLA) in which it operates. We understand identity as a set of positions organized in a semiotic way, as an aesthetic of self that is shaped by interaction with others.

KEYWORDS: Art. Aesthetic. I dentity. Teacher. Distance learning.

E assim se fez o começo...

Quando você trabalha com teatro você começa o contato com arte, você pensa em arte o tempo inteiro, e pra mim que era um adolescente que tinha dificuldade de lidar com umas estruturas assim de pensar o mundo que é própria do momento né? O teatro me ajudou a me inserir no grupo que acho que era uma dificuldade que eu tinha. Então esse contato com a literatura foi muito significativo pra mim em termos de pensar essa coisa da imaginação etc. Mas enfim, aí eu me formei no curso de letras né? Entrei então pra pensar a literatura, entrei para o mestrado em história da literatura na mesma instituição. (Professor Dom).

Esta é a fala de Dom¹, em uma entrevista sobre sua história de vida e acadêmica de como se tornou professor e sobre a importância do teatro em sua vida. Este trabalho apresenta um estudo sobre a construção identitária docente a partir da vivência estética da literatura na EaD. Pretendemos refletir sobre a estética a partir de dois pontos de vista; o primeiro como estética de si na construção identitária de um docente da EaD e, o segundo, a partir da educação estética proporcionada pelas atividades literárias e artísticas disponibilizada nas disciplinas de língua espanhola e literatura dos cursos de letras espanhol e português na modalidade a distância.

O título "Lorqueando" refere-se a um conjunto de poemas que o professor participante desta pesquisa Dom construiu a partir de textos de Garcia Lorca, em que fez dramatizações dos poemas do autor, musicou e os transformou em videopoema, que utiliza para compor seu material para a disciplina de língua espanhola. Ao interpretar os poemas, Dom também constrói a si mesmo, utilizando técnicas de teatro, cinema e literatura. Constrói aulas que impactam o aluno, mas também a si mesmo como autor.

Nosso personagem é, então, um professor que se mescla com o ator, ora atuando em suas produções de videopoemas, ora permanecendo como eu-professor. Os posicionamentos que se adquirem movimentam em um percurso dialógico com o aluno (BORGES; LINHARES; CAIXETA, 2011), mediados por sua produção literária e organizada semioticamente no ambiente educacional de um curso de EaD. Ora professor, ora ator. Sempre um professor-ator, porque "a vida pode se converter assim em uma experiência dramática, ou seja, dramatizada e pode ser contemplada por outros e por nós mesmos como espetáculo." (CASTRO; NUNES; BARBATO, 2010, p. 274). A ideia do professor como personagem de sua construção estética e identitária permeia este texto.

Entendemos que a construção da identidade é algo dinâmico e constante que envolve os posicionamentos de si (HARRÉ; LANGENHOVE, 1999) na relação com os grupos a que pertencemos e nas atividades que desenvolvemos. Portanto a identidade refere-se a um pertencimento e a uma organização de si como forma de se construir a partir das relações dialógicas. A inclusão em um grupo determinado, como o de professores, implica o distanciamento de outros, como o de alunos. Diferentemente da concepção tradicional de identidade, em que esta é expressa por um conjunto de papéis, adotamos aqui a concepção baseada na teoria do posicionamento de Rom Harré (HARRÉ; LANGENHOVE, 1999). Assim, a identidade refere-se a um conjunto de posicionamentos organizados semioticamente como uma estética de si que é significada pela interação com o outro.

A teoria do posicionamento (HARRÉ; MOGHADDAM, 2003) parte da concepção que os atos de fala são lugares (espaços) ideológicos em que as interações verbais tomam forma de construções identitárias de si e do outro. Bakhtin destaca:

É quase total a analogia entre significados das fronteiras temporais e os significados das fronteiras espaciais na autoconsciência que se tem do outro. A descrição fenomenológica dessas experiências - contanto com a descrição não seja perturbada por leis genéricas ou por considerações teóricas externas (o homem em geral, o nivelamento das respectivas posições do eu e do outro, o esquecimento dos valores) - esclarece a diferença fundamental que a importância

342 Fabricia T. Borges, Andrea C. Versuti e Angélica F. Piovesan - Lorqueando: a literatura como vivência ... 
e a organização da temporalidade comporta conforme se trate das experiências que tenho de mim ou da experiência que tenho do outro. (BAKHTIN, 2000, p. 123-124).

Os significados atribuídos às situações e às posições podem ser mudados de acordo com as mudanças de comportamentos e atitudes. Isso só ocorre porque os significados atribuídos às situações estão mudando. Estes significados mudam de acordo com o contexto social. "A teoria do posicionamento vê as posições emergindo sobre o tempo das conversações" (APTER, 2003, p. 23). Não tem uma única interpretação como sendo verdadeira, mas sempre com múltiplas possibilidades.

(...) posições existem como padrões de crenças nos membros de uma relativamente coerente comunidade de fala. "Posições" são sociais no sentido que as crenças relevantes de cada membro são similares aquelas dos outros membros. Claro que nós podemos acessar a similaridade de grupos de crenças de posicionamentos de cada pessoa para aqueles outros somente como cada ator social expressa suas crenças sobre posições. (HARRÉ, 2003, p. 04).

A identidade, então, não é algo estático, mas se movimenta a partir dos contextos dialógicos de seus atores e personagens, estando em contínua construção. Os posicionamentos de si refletem as posturas ideológicas da interação verbal na relação com o outro. Posicionamo-nos frente ao discurso do outro, mas também somos posicionados pelo outro em sua enunciação. A construção identitária é, então, um produto da interação com o outro, organizada semioticamente, em determinado contexto dialógico e é, portanto, estética.

A identidade é percebida a partir de um self dialógico baseado na suposição que há muitas posições do Eu que podem ser ocupadas pela mesma pessoa. Estas posições podem concordar ou discordar, mas estando sempre ligado a uma posição particular no espaço e no tempo.

O termo "posição" tem sido apropriado para se referir aqueles momentários grupos de direitos e deveres para pensar, agir e falar em certas formas que são evidentes no fluxo da vida diária A posição é unida com os tipos de atos que a pessoa naquela posição ser "vista" ou "ouvida" para trabalhar com qualquer instrumento simbólico. (HARRÉ \& VAN LANGENHOVE, 1999).

No romance polifônico, Bakhtin trata do Autor X Herói, descentralizando qualquer perspectiva de existência de um Eu como único. Para ele, há uma multiplicidade de posições representadas pelas vozes do autor, como se fossem outros autores, comunicando-se entre si e com os atores e os personagens. Abordando Bakhtin, Amorim (2006, p. 22) destaca que a "linguagem cotidiana e a estética serão lugares de expressão da contraposição entre o eu e o outro, e, portanto, lugares, fundamentalmente dialógico". Não se pode reduzir a experiência estética a um só, uma vez que ela é expressão da interação e é, portanto, dialógica (BAKHTIN, 1993).

\section{VIDEOPOEMAS, ARTE E DOCÊNCIA}

O professor Dom constrói videopoemas para fins didáticos em suas disciplinas. Ao selecionar, dramatizar e disponibilizar para os alunos, ele também propicia a construção de si como professor no diálogo com os alunos. Os videopoemas podem ser construídos por meio de uma configuração criativa única de cada poema recitado e dramatizado, portanto ao construir artisticamente seu material didático, ele se configura também esteticamente como docente. São palavras sobrepostas, amontoadas, interligadas, formando um significado para as criações poéticas, mas também que traz para si como docente uma expressão estética.

Os textos exibidos em vídeos com imagens, músicas, sons, formam os videopoemas que podem ser vistos como fusão entre poesia e vídeo, poesia digital. [...] “há um deslocamento da poesia, de sua forma canônica de veiculação - o livro - assim como o vídeo perde seu caráter de produto acabado, pois está aberto a interpretações". (FRAGA, 2004, p. 3). Poesia visual, vídeo-poesia, poesia em imagem são algumas denominações também utilizadas.

O videopoema Lorqueando foi construído por Dom a partir de interpretações de alguns trechos de poemas e de peças teatrais de Garcia Lorca. Sua encenação começa com um trecho do poema Deseo (1920) e segue interpretando ao longo do videopoema trechos da peça teatral Bodas de sangue, escrita em 1932, e interpretando Vênus e VII Es verdad. Como fundo musical utilizou as canções da cantora espanhola, Ana Belén. 
No vídeo, postado no AVA pelo professor, os poemas são interpretados em espanhol, propiciando o contato com a língua espanhola e com a literatura, em uma interpretação dramática feita pelo professor, além da ambientação feita por meio da música, também espanhola. O autor dos poemas também reflete as ideologias do professor Dom, que interage com sua forma de organizar a disciplina esteticamente. A voz de Federico Garcia Lorca compõe junto com outras que participam da polissemia de Dom, sua imagem docente.

Federico Garcia Lorca (1898-1936) é um renomado poeta espanhol do século XXI. Poeta e dramaturgo, nasceu em 5 de junho de 1898 em Fuente Vaqueros, Espanha, faleceu em Granada em 1936. Filho de Vicenta Lorca, professora primária, ela quem Ihe ensinou as primeiras letras; casada com Federico García Rodriguez, ambos provincianos e muito ligados à terra granadina. Versátil, sabia aproveitar praticamente as lições de quase todas as tendências e escolas literárias para desembocar no artesanato da palavra, seu ofício maior. Deixou obras de literatura em Poesia, Prosa e Teatro. Garcia Lorca desenvolveu a poesia lorquiana, cujos elementos da poesia e da alma espanhola encontram-se alinhados. É considerado o poeta da imagem, da originalidade, da sugestão e do verso musical (MOTA, 1989).

A escolha do docente sobre o material literário que comporá sua sala de aula virtual configura a identidade virtual de si como professor, posicionando-se a partir deste grupo de alunos.

Enfim, eu penso que ao ser professor no mundo de não leitores no mundo que nós temos hoje em dia é a gente conseguir fazer com que as pessoas que entram dentro do curso de letras se tornem leitores pra depois passar a pensar criticamente esse objeto estudado que é a própria literatura. (Professor Dom).

O videopoema é produzido e veiculado pela Internet e não apenas por poetas. "Assim, os videopoemas, além de possuírem características técnicas diferentes, também abrangem desde a arte abstrata até a expressão singela e ingênua com palavras, sons e imagens das pessoas comuns (teoricamente não-poetas). [...] possui muito da ludicidade do poema tradicional com as palavras e do movimento icônico do videoclip musical." (LIMA, 2008, p.7).

Para a criação do videopoema, é necessário usar a criatividade para a escolha das imagens, das cores e dos movimentos, com também a harmonia na escolha da música. Ele permite interatividade hipertextual quando publicado no youtube e em blogs. Por isso, "o design da página, a interação texto-imagem-som (se houver), os efeitos especiais" são importantes (LIMA, 2008, p. 9).

O videopoeta recriará seu texto com os recursos digitais do computador e será seu próprio editor e distribuidor “[...] pois lançará o seu trabalho na rede, o qual será exposto em uma grande livraria/vitrine eletrônica. [...] ele interage com seus leitores virtuais, através da comunicação eletrônica. [...] agregando ao seu trabalho elementos do espetáculo, do show, da performance, isto é, elementos da corporeidade". (LIMA, 2008, p.4). Na rubrica: teatro do dicionário eletrônico Houaiss (2004), performance significa "espetáculo em que o artista atua com inteira liberdade e por conta própria, interpretando papel ou criações de sua própria autoria".

A organização estética de si do docente funciona também como um impacto na relação com o aluno. No videopoema, o professor apresenta arte e também vira arte. É ele que roteiriza e interpreta os poemas que escolhe para compor sua identidade visual no AVA (ambiente virtual de aprendizagem). A construção em si é uma obra estética que é percebida pelo outro, o aluno, como a imagem do professor. Sua identidade, sua forma de ser, organizada significativamente pelo contexto e pelas interações que promove mediado pelo Ambiente Virtual de Aprendizagem. O AVA é a moldura que dá o tom da relação. Professor e alunos se constroem neste espaço semioticamente organizado, por textos, vídeos, imagens, sons e escritas.

E aí como eu tenho essa facilidade nesse processo de expressividade eu uso da minha voz, da minha imagem pra pensar esses processos. Hoje em dia eu trabalho predominantemente por causa dessa predisposição ao trabalho didático um pouco mais performático que a educação a distância me ajudou muitíssimo a perceber que isso, essa forma, essa outra forma de pensar a educação como uma certa expressividade é algo que (tripudia) no meio acadêmico. (Professor Dom).

É sobre suas histórias e suas habilidades que Dom constrói o seu jeito de ser professor. Oportunizadas pela EaD, na variedade de recursos tecnológicos que são disponibilizados aos docentes e aos alunos. Os recursos tecnológicos são mediadores das atividades e também da imaginação 
sobre a atividade docente. São recursos culturais que acessam as habilidades e as competências, ampliadas pela imaginação e pela atividade. (LEONTIEV, 1978)

[...] então, às vezes eu recito um monte de poemas lá, então, o DOM, ele , depois que a educação a distância possibilitou essa questão da atuação sem preconceito de, porque imagine, no presencial o professor ator [...]. (Professor Dom).

Então, quando Dom, disponibiliza o seu videopoema de Garcia Lorca no AVA, ele está oportunizando um encontro com seus alunos. Em algum momento, o aluno vai assistir ao vídeo, ouvir a poesia, encontrar com o professor. O encontro acontece, em algum espaço do cotidiano da EaD. É a atividade de aluno e do professor que favorece o encontro, o professor quando elabora o material para seu aluno. O aluno quando faz deste material, seu lugar de encontro com o professor.

\section{O DOCENTE COMO CONSTRUÇÃO ESTÉTICA DE SI}

O professor em sua organização de si impacta o outro esteticamente. O estético em mim só é percebido pelo outro (BAKHTIN, 2010), é ele que me organiza em uma construção artística de mim. Eu vivo o artístico, mas é o outro que me percebe esteticamente. "O outro que está de fora é quem pode dar uma imagem acabada de mim, e o acabamento, para Bakhtin, é uma espécie de dom do artista para seu retratado. (AMORIM, 2006, p. 97). Um professor de literatura, em que imagem (físicas e literárias) faz parte de suas histórias e ajuda a elaborar um espaço artístico na relação docente-aluno.

(...) a respeito das coisas porque eu tô me pensando né o que é pro aluno enxergar esse professor que não é aquele mesmo que tá lá no vídeo porque La eu sou extremamente expressivo eu sei disso, eu uso esse meu viés que foi desenvolvido na arte dramática pra conseguir desenvolver um dialogo através da câmera com os alunos fazendo a explanação de determinados conteúdos eu uso da voz, você vai ver nos podcasts eu uso da voz, só não vou fazer agora de frente da câmera eu vou dar os arquivos de áudio depois tem um personagem que eu faço que as vezes eu volto, eu faço esse personagem, (como é esse velho) não, esse velho já é, esse velho já leu o dom Quixote, mas esse velho apareceu bem cá, bem velhinho assim conversando com uma outra professora que ele fazia de conta que era um médico entendeu, mas esses dias eu tava, ah não vou falar... (risos). (Professor Dom).

Para Vigotski (2004, p. 342), longe de ser somente um contágio emocional, "uma obra de arte vivenciada pode efetivamente ampliar a nossa concepção de algum campo de fenômenos, leva-nos a ver este campo com novos olhos, a generalizar e a unificar fatos amiúde inteiramente dispersos". A educação estética passa pela contemplação emocional do objeto artístico, mas mais que isto, pressupõe a superação das percepções imediatas advindas dele para posteriormente organizar comportamentos e pensamentos. "A vivência estética organiza nosso comportamento" (VIGOTSKI, 2004, p. 343).

(...) os livros pertencem à reflexão sobre a arte dramática né, mas aí qdo eu penso no contexto da $E A D$, eu fico pensando num aluno que nunca leu um texto literário que são discutidos em fim nas academias, aí eu fico pensando nesse aluno que só vê televisão , eu não vejo televisão... (Professor Dom).

Dom caminha entre suas produções, seus roteiros e seus alunos. Dialoga. É um professor dialético. Atua. É um professor-ator-diretor-produtor. Produz. Faz do conhecimento cinematográfico uma das habilidades para se construir como professor da EaD.

(...) eu fico pensando né, eu to roteirizando, eu to entendo agora de estrutura de roteiro cinematográfico. Ta, eu entrei na educação a distancia, e eu pensava com o diretor e a diretora o que nós íamos gravar, mas eu não escrevia roteiros, até que eu comecei a me tornar viciado em roteiro de cinema. Comecei a ler, devorar, milhares de livros, comecei a entender a estrutura, comecei a pensar nisso. Aí comprei mais bibliografias a respeito de estrutura de roteiro né, e penso nesse processo de adequação de questões da educação a distância e aí aparece esse professor lá que ta atuando e que ta repensando nesse processo de enquanto identidade, este vídeo que eu estava mostrando anteriormente pra você você vê nitidamente que é uma atuação. (Professor Dom).

A habilidade com imagem e a produção de materiais para compor o AVA destacam-se com um das atividades evidenciadas na nova EaD. A educação a distância mediada pela Internet e pelo computador permite novas formas do ser professor. No ensino presencial, ele também poderá construir materiais 
para apresentar sua arte dramática, mas este local não possui a magia da espetacularidade. A tela do computador, a tela do mundo, ali lançamo-nos ao mundo. A nova forma de espetáculo (DEBORD, 1989) está nos blogs, nos sites, no espaço cibernético. O computador propicia outras formas de fazer arte, outras imagens, outros vídeos, outros sons. Outras identidades.

$\mathrm{Na}$ construção de materiais para a EaD o professor deve observar alguns critérios relevantes. Estes materiais (impressos ou digitais) devem garantir, sobretudo, que efetivamente haja a interação e a construção do conhecimento. Para isso, precisam ser constituídos de elementos de forma e conteúdo organizados segundo um planejamento prévio com o objetivo de diminuir a distância e aproximar os sujeitos por meio da escolha adequada e coerente da linguagem e de seus recursos. Em síntese, pode-se dizer que estes materiais devem ser dialógicos, dinâmicos, criativos e abertos para novas possibilidades de experiência.

\begin{abstract}
Do ponto de vista metodológico, estar aberto às experiências e poder refletir sobre elas é a possibilidade de pensar, não com uma camisa de força que formata, mas como um movimento de abertura que considere as múltiplas possibilidades dos conhecimentos, postas na mesa através dos meios interativos de comunicação contemporâneos. Como quer Paul Feyeranbend, é necessário "[...] enfatizar a ambiguidade essencial de todos os conceitos, imagens e noções que pressupõem mudança". (LARROSA, 1996, p. 195).
\end{abstract}

Segundo Boufleuer (1997), as interações educativas devem ser coordenadas com a reprodução dos componentes simbólicos do mundo da vida: a cultura, a sociedade, a personalidade. Um dos grandes desafios da Educação no contexto atual não é simplesmente fazer com que os sujeitos aprendam, mas promover outras formas de aprendizado que não seja mais linear, expositivo, unilateral e impositivo, mas múltiplo, ampliado e, sobretudo, participativo, sendo assim mais coerente com a realidade que os cerca e com os estímulos aos quais eles estão submetidos. Para isso, alguns professores, como Dom fazem uso da linguagem hipertextual como forma de ampliar sua competência comunicativa, pois esta é a que apresenta maior proximidade com a realidade (HABERMAS, 1999).

Isto porque a Internet, além de apresentar um maior e mais efetivo acesso às informações, pode interferir na forma como estas informações serão utilizadas na aprendizagem de conteúdos significativos. Nestes novos meios, as mensagens veiculadas devido às suas características de fluidez, numeralização, plasticidade e instantaneidade são mais facilmente suscetíveis às interferências dos receptores que podem contribuir diretamente na sua construção e tornarem-se também autorprodutores do conhecimento ou dito de outra forma, sujeitos da comunicação e do processo cognitivo (RENÓ; VERSUTI; GONÇALVES; GOSCIOLA, 2011).

A utilização desta linguagem hipertextual é cada vez mais recorrente, pois encontra respaldo no comportamento ativo dos sujeitos no ciberespaço. Segundo Dan Gilmor (2005), o receptor passa a ser emissor, mas pensamos que mais do que isto, eles são interlocutores. O leitor, por sua vez, assume o papel de colaborador, ou de coautor e, dessa forma, o leitor também é detentor da mídia, juntos compõem uma dialogia, em que um e outro participam com suas vozes do que entendem do outro e de si.

A experimentação estética do professor na EaD traz significados para sua atividade também a partir das características da imagem eletrônica, tais como sua maleabilidade, flexibilidade, anamorfoses e distorções causadas por sua baixa definição, a possibilidade de sua manipulação temporal e sua capacidade de metamorfose. As atuais tendências dos meios audiovisuais atentam para uma nova complexidade das imagens produzidas a partir da sua transformação, mestiçagem e multiplicidade respondendo a necessidades novas e emergentes (MACHADO, 1996).

(...) começou a atuação eu to esperando, eu to experimentando a câmera, eu to com o controle da câmera na minha mão e que eu chego La eu inventou vou fazer isso, aquilo, mas não, eu chego lá na hora e tipo assim oh, eu digo assim 10 minutos antes, eu vou entrar mas quero o controle porque o controle tem os botõezinhos que determinam o enquadramento assim, assim, assim aí eu memorizo 3 só, só três porque não dá pra memorizar seis na hora mais todos os conteúdos que eu tenho que trabalhar na hora, mais isso, aquilo né e ai eu começo de uma maneira muito especifica que tem um caráter simbólico sendo trabalhado ali não é, oi me lembro uma vez quando comecei a trabalhar essa coisa pra fazer, oh, cantar um pouquinho no inicio da aula que eu cantava assim, mas por que cantar, poxa to trabalhando com literatura, por que cantar , eu to trabalhando com arte por que não deixar a arte viva, deixar a arte viva pra não leitores isso dá pra fazer uma tese na verdade, por exemplo, você está oralizando, não, você está 
transformando em imagem e som textos literários você tá fazendo pequenos filmes que apóiam você como uma espécie de pre-produção pra aula via satélite. (Professor Dom).

A imagem eletrônica não é mais inscrição no espaço, mas uma inscrição do tempo no espaço, na qual cada linha e cada camada corresponde a um tempo distinto. Nas palavras de Machado (2008), “A imagem completa, o quadro videográfico, não existe mais no espaço, mas na duração de uma varredura completa da tela, portanto no tempo. A imagem eletrônica não é mais como eram as imagens anteriores, ocupação da topografia de um quadro, mas síntese temporal de um conjunto de formas em mutação".

Nesta dinâmica de se construir como professor da EaD, Dom interage com a atividade da EAD, com sua história, com a literatura, com seus colegas da EaD, com seus alunos. Constrói sobre si, como docente, uma identidade também que é virtual. O virtual, em outros lugares, entrecruza com sua identidade docente (HALL, 1996).

(...) tá cheio de professor ali e ai eu fico sem jeito, quando a gente ta olhando pra câmera assim oh, é a gente e a câmera é mais fácil de lidar assim do que 700 pessoas que estão vendo vc agora num outro lugar que dialogam, é confuso pra mim ainda, acho que essa forma de desabafo é por que há uma certa confusão mesmo de se pensar como professor ainda nessa modalidade, há né, uma vez eu tava conversando com um professor da educação a distancia que trabalha numa universidade de são Paulo e ele me contou essa situação de estar numa situação bêbado numa praia (risos) e ai chega uma aluna imagina, você I no vídeo, o aluno te conhece há dois anos e você tá bêbado numa praia (que situação) uau, porque o aluno idealiza, aí está a sociedade do espetáculo pra ser pensada por você viu de como é essa confusão ai, de como é essa construção de identidade do sujeito que ta lá no momento da atuação. (Professor Dom).

O professor Dom, também desenvolve um blog no qual muitas vezes utiliza de seus materiais didáticos para falar de si. Participa de um espetáculo (DEBORD, 1989) virtual que desfragmenta um eu único, mas que se organiza em múltiplas formas, se posiciona em vários momentos comunicativos. A identidade do docente na EaD se compõe também com as identidades virtuais de Dom na rede. São vários posicionamentos de si, no facebook e nos blogs que desenvolve. Nestes lugares virtuais, também constrói a si como docente, como sujeito da rede (Internet) em que dialoga com vários grupos, inclusive com os alunos. A identidade virtual de Dom nas redes também se organiza como uma atividade estética de si. Desloca, então, seus posicionamentos da EaD para a rede, ampliando seus posicionamentos docentes e configurando várias formas estéticas de si.

\section{ÚLTIMAS REFLEXÕES}

Falar de identidade na educação a distância nos faz refletir sobre a arte e a estética em uma construção dialógica, em que a relação docente-aluno está mediada pela identidade virtual e docente do nosso entrevistado. O uso da literatura espanhola para a construção do videopoema Lorqueando demonstra que a era da web é um facilitador das relações sociais e constitutivas de si, ao mesmo tempo possibilita refletir sobre a ampliação e a reconfiguração das interações comunicativas e expressivas de si.

Pensar nas novas formas de constituição do "eu" e do "outro" com o uso das tecnologias nos permite compreender que há uma nova significação da identidade. O acesso a novos signos que fluem pelo ciberespaço, as novas formas de pensar e ver o mundo permite essas significações (MARTINO, 2010).

Nas publicações na web de modo geral, seja nos blogs ou mesmo nas produções dos vídeos que são publicados no AVA, há uma produção de identidades que colaboram na construção de si, do professor da $\mathrm{EaD}$, pois ele compartilha imagens, textuais ou visuais, que representam um pouco de si, ou a visão que ele quer que tenham dele. Há a possibilidade da construção de si no sentido de uma invenção da identidade, na qual o íntimo passa a ser visível em forma de espetáculo e arte.

\section{REFERÊNCIAS}

AMORIM, Marília. Ato versus objetivação e outras oposições fundamentais no pensamento bakhtiniano. FARACO, C. A.; TEZZA, C.; CASTRO, G. (Orgs). Vinte ensaios sobre Mikhail Bakhtin. Petrópolis, RJ: Ed. Vozes, 2006. 
APTER, M. F. Motivational styles and Positioning Theory. In. HARRÉ, R.; \& MOGHADDAM, F. The Self and others: positioning individuals and groups in personal, political, and cultural contexts. Praeger Publishers, 2003.

BAKHTIN, Mikhail. Estética da Criação Verbal. 3. ed. São Paulo: Martins Fontes, 2000. Questões de Literatura e de Estética: a teoria do romance. 6. ed. São Paulo: Hucitec, 2010. Para uma filosofia do ato. TEZZA, C. Trad. Não publicada. Curitiba, 1993.

BORGES, Fabrícia T.; LINHARES, Ronaldo N.; CAIXETA, Juliana E. O professor de EAD: Significados e contradições. Educação a Distância e as Tecnologias da Inteligência: novos percursos de formação e aprendizagem. 1. ed. Maceio- AL: EDUFAL, 2011, v. 1, p. 83-116.

LARROSA, J orge. Notas sobre experiência e o saber de experiência. 1996. Disponível em: http://www. anped. org. br/rbe/rbedigital/RBDE19/RBDE19_04_JORGE_LARROSA_BONDIA.pdf. Acesso em: 28/03/2012

BOUfLEUER, José Pedro. Pedagogia da ação comunicativa: uma leitura de Habermas. Ijuí : Ed. UNIJUÍ, 1997.

NUNES, Daniele; CASTRO, Jorge; BARBATO, Silviane. La imaginación creadora: aspectos históricosgenealógicos para la reconsideración de una psicologia de la actividad y la mediación y la mediación estética. Estudios de Psicología, 31 (3), 253-277, 2010.

DAN GILMOR, Dan. Nós, os media. Lisboa: Editorial Presença, 2005.

DEBORD, Guy. A Sociedade do Espetáculo. Rio de Janeiro: RJ,Contraponto, 1989.

FRAGA, A. A. Imagem, performance e texto na videopoesia. Disponível em: http://www.letras.ufmg.br/ atelaeotexto/pesquisaadriana.htm. 2004. Acesso em 18 de março de 2012.

HALL, Stuart. Identidade Cultural e Diáspora. Revista do PatrimônioHistórico e Artístico Nacional, n.24, p.68-75, 1996.

HARBEMAS, J. Teoría de la acción comunicativa I: Racionalidad de laacción y racionalización social. Madrid: Taurus, 1999.

HARRÉ, Rom; MOGHADDAM, F. Introduction: The Self and Others in Traditional Psychology and in Positioning Theory.In. HARRÉ, R.; MOGHADDAM, F. The Self and others: positioning individuals and groups in personal, political, and cultural contexts. Praeger Publishers, 2003.

HARRÉ, Rom; VAN LAGENHOVE, Luk. Positioning Theory. Blackwell Publishers: Massachusetts, 1999.

HOUAISS, Antonio. Dicionário eletrônico da língua portuguesa. 2004. Cd-ROM.

LEONTIEV, Alexei, N. O desenvolvimento do psiquismo. Lisboa: Horizonte. 1978.

LIMA, L. R. O vídeo-poema como performance: Movimento e corporeidade virtual da palavra. Revistas Tabuleiro de Letras. Linguagens: Práticas, Discursos e Mediações. Ano 1. P. 1-11No. 01 - junho/2008. Disponível em: <http://www.tabuleirodeletras.uneb.br/secun/capa_edicaol.htm>. Acesso em: 18 de março de 2012.

LORCA, Garcia. Narciso. Disponível em <http://users.fulladsl.be/spb1667/cultural/lorca/canciones/amor/ narciso.html>. Acesso em 19 de março de 2012.

LORCA, Garcia. Deseo. 1920. Disponível em <http://www.poesi.as/fgllp054.htm>. Acesso em 20 de março de 2012.

LORCA, Garcia. Bodas de Sangue. 1932. Disponível em: <http://federicogarcialorca.net/mp3/leonardo_y_ la_novia.htm>. Acesso em 20 de março de 2012.

LORCA, Garcia. Venus. Disponível em: <http://langues2.ups-tlse.fr/Espagnol/Poesia/Venus.htm>. Acesso em: 20 de março de 2012.

348 Fabricia T. Borges, Andrea C. Versuti e Angélica F. Piovesan - Lorqueando: a literatura como vivência ... 
LORCA, Garcia. VII Esverdad. Disponível em: <http://users.telenet.be/gaston.d.haese/lorca_andaluzas. html>. Acesso em: 20 de março de 2012.

MACHADO, A. Pré-cinema \& pós-cinemas. 5. ed. Campinas, SP, $2008 \mathrm{~b}$.

MACHADO, R. 2006. in: A imagem eletrônica, problemas de representação, p. 76. Apud: Santaella, Lúcia. Winfried Nöth. Imagem. São Paulo: Iluminuras, 1998.

MOTA, A. V. B. Obra poética completa de Federico Garcia Lorca. Trad. William Agel de Mello, 5. ed. Brasília: Editora Universidade de Brasília, 1989.

RENÓ, VERSUTI, GONÇALVES, GOSCIOLA. Narrativas transmídia: diversidade social, discursiva e comunicacional. Palabra Clave, v. 14, número 2, dezembro 2011, p.201-115.

VIGOTSKI, LEV. Psicologia Pedagógica. São Paulo: Martins Fontes, 2004.

NOTAS

1 O nome Dom é um pseudônimo que iremos usar para garantir a privacidade do professor participante desta pesquisa.

Artigo recebido em $17 / 07 / 2012$

Aprovado em 30/08/2012 